\title{
Development of a Multi-Sensor Micro Reactor System for cell-based analyses
}

\author{
Andrea Böhme ${ }^{1}$, Gregor Gatomski ${ }^{1}$, Sylvio Schneider ${ }^{1}$, Andreas-H. Foitzik ${ }^{1}$ \\ ${ }^{1}$ Technical University of Applied Sciences Wildau, Bahnhofstr.1, 15745 Wildau, Germany, \\ aboehme@th-wildau.de and ggatomsk@th-wildau.de
}

\begin{abstract}
Summary
The classical designs of bioreactors make it possible to realize optimum growth conditions for biological cultures by scalable controlling of the environmental factors. However the increasing complexity of these organisms or in vitro models requires a modern redesign and corresponding unique individual peripherals to simulate realistic living conditions and ensure a targeted operation. The challenge of this project is the up to today insufficient developed sensor or sensor arrays for the monitoring of reactions inside the microscaled bioreactor and on the other side to externally control these processes. The aim of this work is therefore the development and optimization of a human in vitro lymph node with integration of an in-line analytics as a disposable test system.
\end{abstract}

Key words: micro reactor system, micro bioreactor, multi sensors, artificial lymph node, and plastics engineering.

\section{Motivation}

In the classical bioreactors today optimum growth conditions for biological cultures can be realized and changes in environmental factors are controlled scalable in that environment. The increasing complexity of these organisms or in vitro models requires the bioreactor, a modern design and corresponding unique individual peripherals to simulate realistic living conditions and ensure a targeted operation. The problem is the up to today insufficient developed sensor or sensor arrays for the monitoring of reactions inside the bioreactor and on the other side to externally control these processes. Also the design of such a bioreactor must ensure an easy manageability and a low risk of contamination to protect users and samples as well [1,2].

Another challenge is that in most cases of modern active biopharmaceutical drugs and vaccines an effective detection by comprehensive analysis is only partially given. Also most "simple" cell-based assays are often not suitable due to lack of tissue and organ function $[3,4]$.

\section{Aim}

The aim of this work is the development and

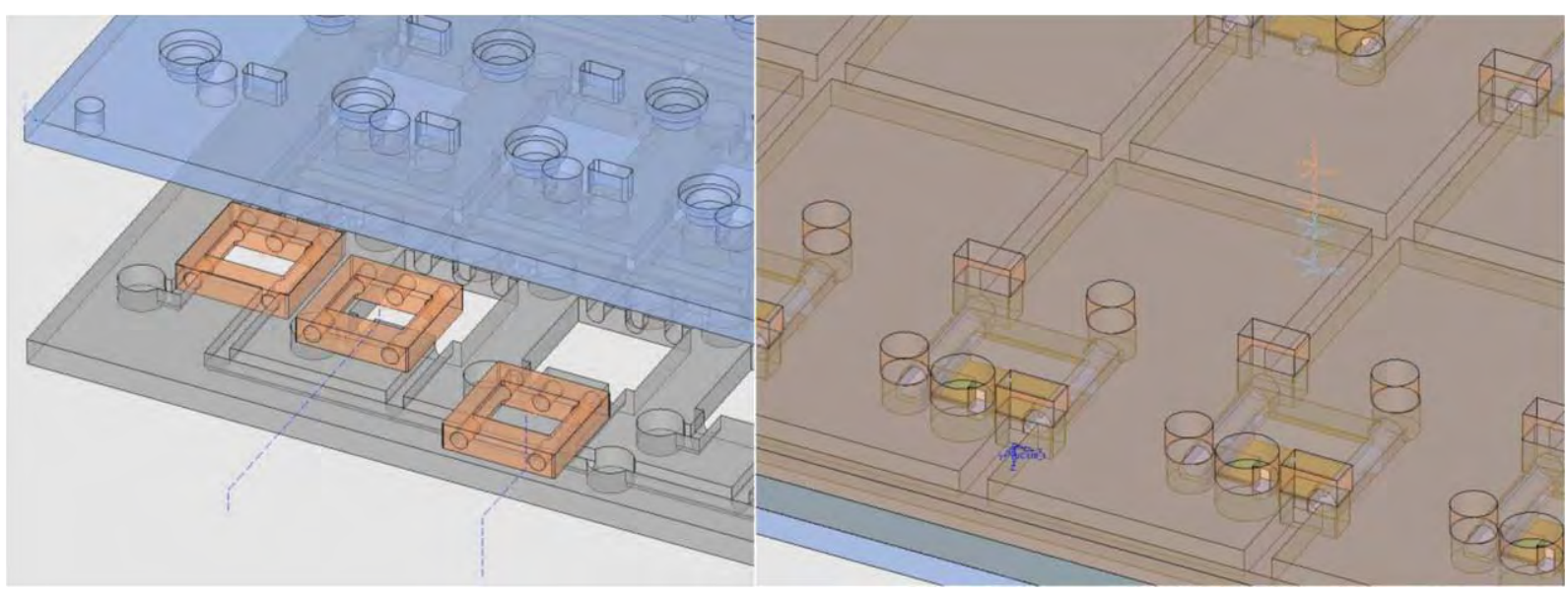

Figure 1: Design variants of the bioreactor and the bioreactor system 


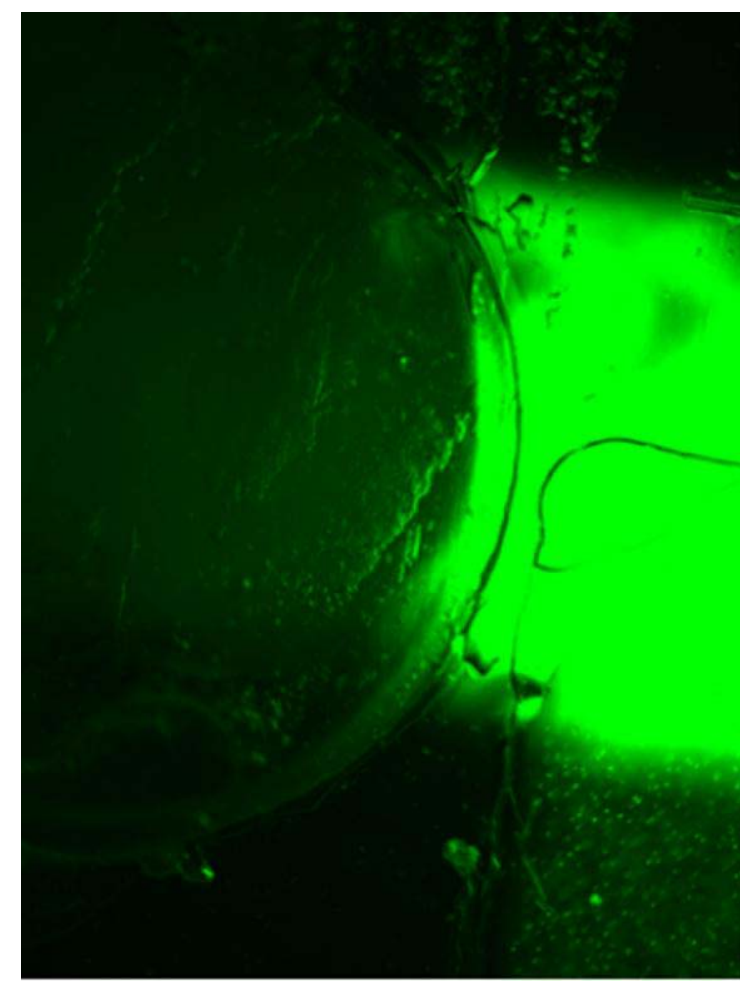

Figure 2: Test result in the area of junction of the special fiber to the medium transfer channel

optimization of a human in vitro artificial lymph node with integration of an in-line analytics as a disposable test system. The bioreactor for the artificial lymph node (ALN) is developed as an alternative to animal models $[5,6]$. In the resulting miniaturized bioreactor system lymphocytes and other cells can be cultured and examined in very small volume. The ALNcell culture system is shaped like a so called microtiter-plate and supplies several microfluidic reactors for parallel analyses.

\section{Strategy and Results}

For design and construction a complex technology chain from Computer Aided Design and Computer Aided Manufacturing - known as $C A D$ and $C A M$ - was used for prototyping and tooling. Afterwards each component of the ALN-cell culture system was manufactured via plastics technology with micro-machining to component manufacture by injection molding machine [7].

For various applications it has become necessary to develop different designs of the reactor system which is exemplary shown in figure 1.

The components made of polymer materials like polycarbonate or polysulfone were joined by two different bonding methods, first via a polymerization binding agent and second by an adhesive bond. The advantage of the used binding agent based of polymerization is the determinability of its setting through polymerization rate via light intensity and irradiation time. This is the critical factor for the tightness of incorporated special fibers to the main reactor chamber. Tests regarding the leaking were already successfully performed (figure 2). It was applying a new fluorescencebased method.

In figure 3 is shown one of the via cutting technologies manufactured bioreactor setups. The bioreactor was to test for cell compatibility. For this purpose, different cell cultures were cultured in the bioreactors for a defined test period. The results were consistently positive.

For a low-price and more efficient manufacturing, the subsequent bioreactor slides will be produced via an injection molding machine. In contrast to the usual approach in tool manufacture each redesign was required a complete tool change it was used an inlay based quick-change system for injection mold tools. Therefore it were produced the special inlay tools.

Additionally to optimize the cultivation conditions a suited heating system including a unique thermosensor array was developed and

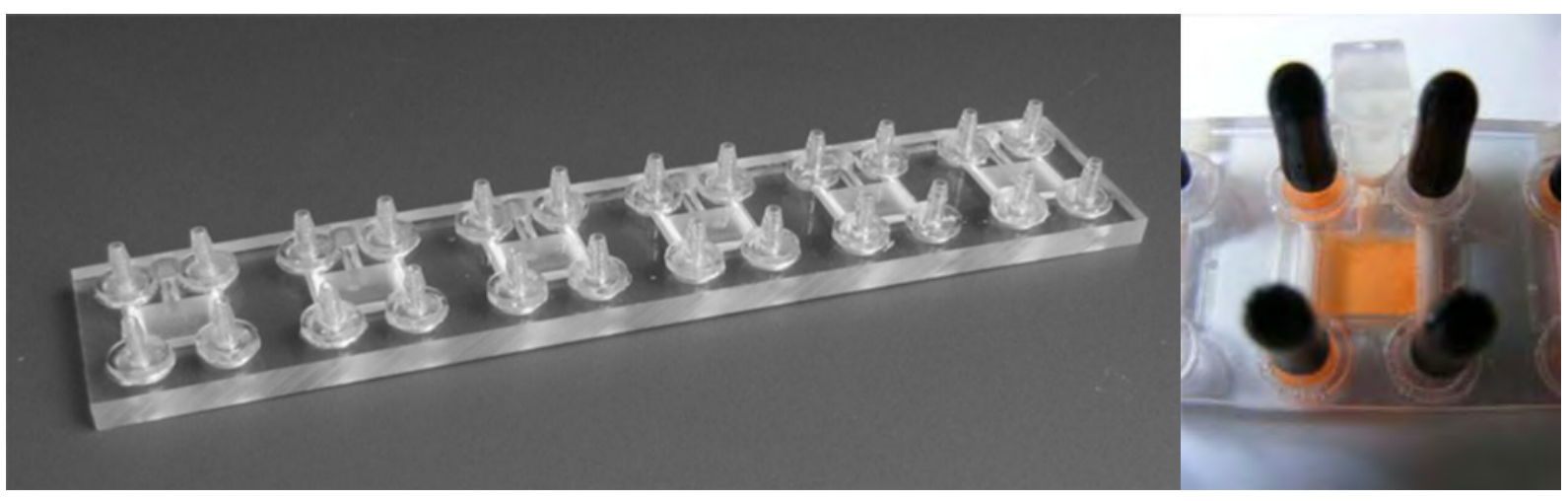

Figure 3: Setup of an artificial lymph node cell culture system (left) and a single reactor chamber (right) 
combined with a NI LabView based regulatory system (figure 4).

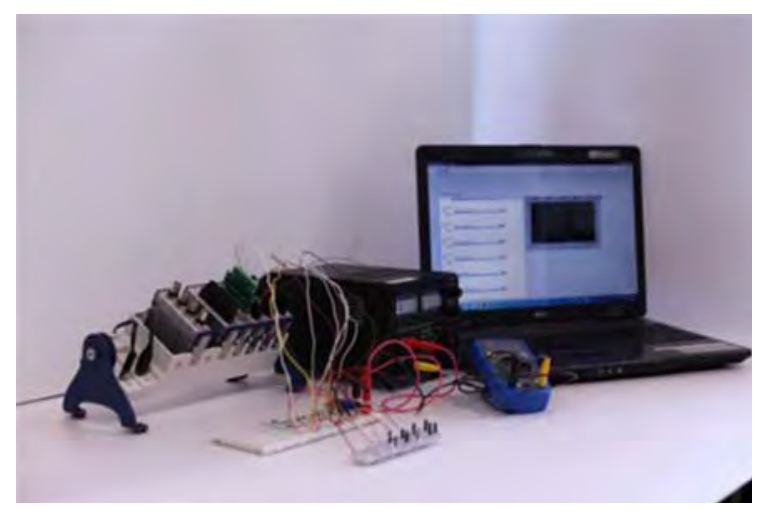

Figure 4: Regulated heating system for the bioreactor system

As a heat source a power MOSFET was used, which converts its electrical power loss in heat energy. Then the converted thermal energy is absorbed by a heat spreader and fed to the corresponding reactor areas. The temperature sensor was conceptualized as in build-in detector. A regulatory system was realized via a PID algorithm.

This temperature control system can be understood as a prototype for other sensor types.

\section{Outlook}

For the future additional sensors need to be implanted into the system to detect various parameters such as oxygen and lactate. The existing LabView based software interface will be the initial point for an adapted end version. A next starting project will be the integration of a by the Leibnitz Institute of Innovate Microelectronics (IHP) developed viscosity based and temperature depended complex glucose sensor technology into the system [8]. Furthermore the implementation of a $\mathrm{pH}$ sensor into or near the bioreactor slide was beginning recently.

On the long run we are looking forward to modify the ALN-system into a complete standalone system with several implemented sensor arrays and the associated periphery.

\section{References}

[1] SCHÜGERL, K.: Reaktionstechnische Grundlagen zur Auslegung und zum Betrieb von Bioreaktoren, Teil 1. Chemieingenieurtechnik 1983; 56 (2), 123-134.

[2] AI, W., GUO, S., QIN, L. and TANG, Y. (2008): Development of a ground-based micro-algae photo-bioreactor. Advances in Space Research 41 (5), 742-747.

[3] RIVALDI, J.D., SARROUH, B.F. and DA SILVA, S.S. (2008): An evaluation of different bioreactor configurations with immobilized yeast for bioethanol production. International Journal of Chemical Reactor Engineering 6, Article A115.

[4] RADISIC, M., MARSANO, A., MAIDHOF, R., WANG, $Y$. and VUNJAK-NOVAKOVIC, G. (2008): Cardiac tissue engineering using perfusion bioreactor systems. Nature Protocols 3, 719-738.

[5] SUEMATSU, S., and WATANABE, T. (2004): Generation of a synthetic lymphoid tissuelike organoid in mice. Nat Biotechnol. 22, 15391545.

[6] GIESE, C., DEMMLER, C.D., AMMER, R., HARTMANN, S., LUBITZ, A., MILLER, L., MÜLLER, R., MARX, U. (2006); A Human Lymph Node In Vitro - Challenges and Progress. Artificial Organs 30(10), 803-808.

[7] GATOMSKI, G., BÖHME, A., KOWOLIK, J., LIETZAU, K.-H., EDEL, C.-H., FOITZIK, A.-H.: Manufacturing for Life Sciences and Medical Engineering - Prototyping of Plastic Moulded Components with regards to Just-in-time Market Maturity. Proceedings of 10. International Scientific Conference New Ways in Manufacturing Technologies, 17-19. June 2010.

[8] BASMER, T., GENSCHOW, D., FROEHLICH, M., and BIRKHOLZ, M. (2012): Energy budget of an implantable glucose measurement system. Biomed Tech 2012; 57 (Suppl. 1), 259-262. 